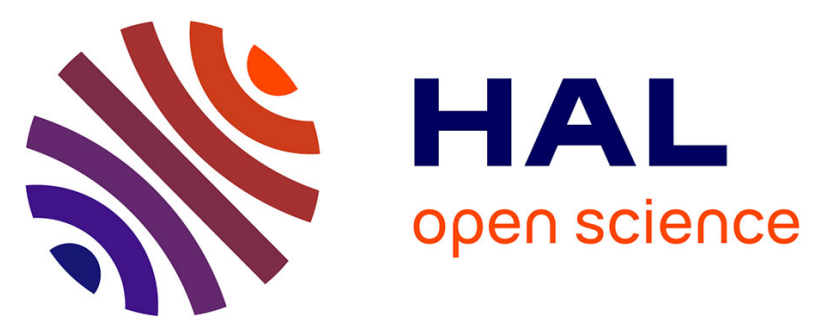

\title{
Weight Loss After Sleeve Gastrectomy: Does Type 2 Diabetes Status Impact Weight and Body Composition Trajectories?
}

Marc Diedisheim, Christine Poitou, Laurent Genser, Chloé Amouyal, Jean-Luc Bouillot, Cécile Ciangura, Jean-Michel Oppert, Karine Clément, Judith Aron-Wisnewsky

\section{To cite this version:}

Marc Diedisheim, Christine Poitou, Laurent Genser, Chloé Amouyal, Jean-Luc Bouillot, et al.. Weight Loss After Sleeve Gastrectomy: Does Type 2 Diabetes Status Impact Weight and Body Composition Trajectories?. Obesity Surgery, 2020, 10.1007/s11695-020-05075-1 . hal-03021028

\section{HAL Id: hal-03021028 https://hal.sorbonne-universite.fr/hal-03021028}

Submitted on 24 Nov 2020

HAL is a multi-disciplinary open access archive for the deposit and dissemination of scientific research documents, whether they are published or not. The documents may come from teaching and research institutions in France or abroad, or from public or private research centers.
L'archive ouverte pluridisciplinaire HAL, est destinée au dépôt et à la diffusion de documents scientifiques de niveau recherche, publiés ou non, émanant des établissements d'enseignement et de recherche français ou étrangers, des laboratoires publics ou privés. 


\section{Weight loss after sleeve gastrectomy: Does Type 2 diabetes status impact weight and body composition trajectories?}

Short running title: Post-sleeve weight loss and Type 2 diabetes

\section{Original article}

Marc Diedisheim ${ }^{1,2}$ MD-PhD, Christine Poitou ${ }^{1,3}$ MD-PhD, Laurent Genser ${ }^{3,4}$ MD-PhD, Chloé Amouyal 3,5

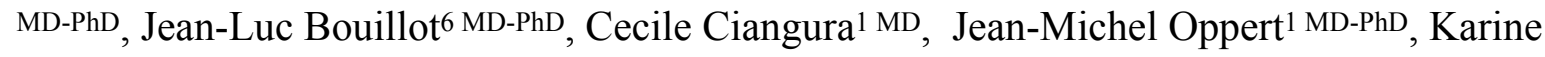
Clément 1,4 MD-PhD, Judith Aron-Wisnewsky1,3 MD-PhD

${ }^{1}$ Assistance Publique-Hôpitaux de Paris, Nutrition department, Pitié-Salpêtrière hospital, CRNH Ile de France, Sorbonne Université, Paris, France

${ }^{2}$ Assistance Publique-Hôpitaux de Paris, Cochin Hospital, Department of Diabetology, Paris Descartes University, Paris, France

3Sorbonne Université, INSERM, Nutrition and obesities: systemic approaches (NutriOmics) research unit, UMRS U1269, Paris, France

${ }^{4}$ Assistance Publique-Hôpitaux de Paris, Pitié-Salpêtrière Hospital, Department of Digestive and Hepato-Pancreato-Biliary Surgery, Sorbonne université, Paris, France

${ }_{5}^{5}$ Assistance Publique-Hôpitaux de Paris, Diabetology department, Pitié-Salpêtrière hospital, Sorbonne université, Paris, France

${ }^{6}$ Saint-Joseph Hospital, Department of Digestive Surgery Department, Paris, France;

Word count: 2900 
Number of tables and figures: 1 table, 2 figures

Corresponding author:

Dr Judith Aron-Wisnewsky.

Pitié-Salpêtrière Hospital, - Batiment IE3M, 6th floor

46-83 Boulevard de l'Hôpital, 75013, Paris.

Tel: 33(0) 142177541.

E-mail: judith.aron-wisnewsky@aphp.fr

Funding. Clinical study was sponsored by the Assistance Publique-Hôpitaux de Paris, and funding of this cohort obtained by several programs: Clinical Research contracts for clinical investigation (PHRC 02076 to KC, CRC P050318 to CP and CRC-FIBROTA to JAW and KC) and the French National Agency of Research ANR ("Investissement d'Avenir" FORCE network (F-Crin)), Metagenopolis grant ANR-11-DPBS-0001 and IHU-ICAN (reference ANR-10IAHU-05, BARICAN research project).

Acknowledgments. We thank Dr Florence Marchelli MD (NutriOmics and Human Nutrition Research Center (CRNH Ile de France) and Rohia Alili (NutriOmics and Human Nutrition Research Center (CRNH Ile de France) for their contribution to the database and biobanking and Valentine Lemoine for patient follow-up (ICAN).

Conflict of Interest. No conflict of interest relevant to this article were reported. 



\begin{abstract}
Introduction/ purpose: Sleeve gastrectomy (SG), the most frequently performed bariatric procedure, induces marked weight-loss, but with high inter-individual variability. Since Type 2 Diabetes (T2D) negatively impacts weight-loss outcomes after Roux-en-Y gastric bypass (RYGB), we herein aimed to evaluate whether, and how T2D status may influence weight-loss and body composition changes in individuals with or without T2D after SG.
\end{abstract}

Material and methods: We retrospectively included individuals with obesity operated from SG and prospectively followed at our center: 373 patients including 152 with T2D (40\%). All subjects' clinical characteristics were collected before and during 4-year of follow-up post-SG. Linear mixed models were applied to analyze weight-loss trajectories post-surgery.

Results: Compared to individuals with obesity but no T2D, those with T2D before SG displayed lower weight-loss at one year $\left(21\right.$ vs. $27 \%$ from baseline, $\left.\mathrm{p}<10^{-3}\right)$. This difference was accentuated in patients with poorer glucose control $(\mathrm{HbA} 1 \mathrm{c}>7 \%)$ at baseline. Furthermore, patients with T2D underwent less favorable body composition changes at 1-year post-SG compared to individuals without T2D (\% fat mass reduction: $28 v s .37 \%, \mathrm{p}<10^{-3}$ respectively).

Conclusion: When undergoing SG, subjects with obesity and T2D who have poor pre-operative glycemic control, display reduced weight-loss and less improvement in body composition compared to patients with obesity but without T2D. This result suggests that glycemic control prior to surgery is important to take into account for the outcome of bariatric surgery.

Key words: bariatric surgery, obesity, sleeve gastrectomy, weight-loss, Type 2 diabetes, body composition. 

Although bariatric surgery (BS) generally induces important and sustained weight-loss (1), the amount and trajectories of weight reduction display major inter-individual variability $(2,3)$. Several reports, mostly focused on patients undergoing Roux-en-Y gastric bypass (RYGB), have identified factors involved in poorer weight-loss response. In the large US-based LABS study, with a 7 years follow-up post-RYGB, increasing age, lower baseline BMI, abnormal kidney function, smoking status and eating behavior disorders were identified as clinical parameters involved in poorer weight-loss response (4). Importantly, Type 2 diabetes (T2D) was the most important clinical criteria associated with lower weight-loss outcomes at 3 (5) and 7-years postRYGB (2), concordant with results from our group obtained in independent cohorts who underwent RYGB $(6,7)$.

Since BS is now part of the treatment algorithm for individuals with T2D (8), both for weight reduction and glucose control improvement, one can anticipate a burst in the already high number of BS candidates. SG now represents the most performed BS type worldwide (9). To date however, no international consensus recommend a specific BS type over another in patients with T2D. In usual candidates to BS, weight-loss appears similar between SG and RYGB $(3,10,11)$. However, long-term follow-up regarding weight-loss trajectories post-SG remain scarce, and when available, are often pooled with those post-RYGB(12). Thus, it remains unclear whether T2D status negatively impacts weight-loss response post-SG as already demonstrated post-RYGB $(2,4,7)$.

Furthermore, given the specific impact of adipose-tissue compartments on obesity-related metabolic complications (13), rather than weight-loss per se, it could be more relevant to evaluate body-composition improvement (i.e. loss of total fat-mass (FM) and maintenance of fat- 
free mass (FFM)) and the reduction of the most important ectopic fat (i.e. visceral fat that can be derived from DXA-assessed trunk-fat mass). While similar body composition improvement postRYGB and SG have already been observed (14), the effect of T2D status on these changes has not yet been studied.

Therefore, we aimed to compare the effects of SG in severely obese patients with and without T2D on weight-loss trajectories and changes in selected body composition indicators to assess SG-induced beneficial outcomes in individuals with T2D.

\section{Research Design and Methods}

\section{Study design and participants}

Using our prospective BS cohort ("BARICAN" recorded in CNIL n¹222666), followed at the Nutrition department of Pitié-Salpêtrière university hospital (Paris, France) and meeting with BS guidelines (15), we retrospectively selected all patients who underwent SG, with complete follow-up data set at one year post-SG. We solely selected patients with a primary SG intervention, since revision surgery performs worse in terms of weight-loss outcomes than primary intervention (16-18). Following both national and international guidelines (19), preparation to surgery and post-operative follow-up were performed in a standardized manner (20), , by our multidisciplinary team. In line with national guidelines (19), glucose control was optimized prior to surgery (i.e. more frequent outpatient visits or if needed short hospitalization just before the intervention),. SG surgical technic was performed in a standardized manner by all the surgeons in the team (21). Ethical approval was obtained from the French Research Ethics Committee of CPP Ile de France- $1 \mathrm{~N}^{\circ} 13533$, and by Commission nationale de l'informatique et 
des libertés No. 1222666.

\section{Bio-clinical and anthropological parameters}

Anthropometric variables and patient's medical history and their related treatments (i.e. hypertension, obstructive sleep apnea, dyslipidemia, cardiovascular diseases, joint diseases, stable depression, and other systemic diseases unrelated to obesity) were collected at baseline, 1year post-BS and until the last follow-up visit (mean 2.7 years, median 2 years, interquartile 2-3). We calculated the Framingham score at baseline. After surgery, we gathered patient's complications which are detailed in supplemental material Before surgery and during follow-up visits, blood samples were collected after a 12-hour overnight fast. Body composition by wholebody, dual-energy X-ray absorptiometry scan (DXA, Hologic Discovery W) was performed to assess fat-free (FFM), fat (FM) and trunk-fat mass, as described (14). Body regions of interest (i.e. trunk) were delineated with the use of specific anatomical landmarks (14). For all patients, right-side half-body scans were carried out from which whole-body composition was subsequently extrapolated (22). Percent body fat was defined by (total fat mass (kg)/body weight (kg) x 100). Percent android-fat mass was defined by (trunk-fat mass $(\mathrm{kg}) /$ total fat mass $(\mathrm{kg})) \mathrm{x}$ 100.

\section{Statistical analyses}

Data are expressed as mean \pm SD for continuous variables and $n(\%)$ for categorical variables. Changes in android FM proportion was calculated as follows: $100 *[$ (percent android FM at 1year post-BS)-(baseline percent android FM)]/(baseline percent android FM). As data were not normally distributed, differences between groups were assessed using non-parametric tests, namely Mann-Whitney $U$ test for non-paired analyses and Wilcoxon test for analysis of paired 
data. For comparisons of three or more groups, Kruskal-Wallis ANOVA was used followed by Dunn's method for post-hoc comparisons with Bonferroni correction. Categorical and binary variables were tested by the two-tailed Pearson chi-square test or Fisher exact test accordingly. For analysis of covariance (ANCOVA), dependent and explanatory variables are detailed for each analysis; we checked that $95 \%$ of the residuals were in the interval $[-1.96,1.96]$ (minimal 94\%). We used a longitudinal growth mixture model, which enables to group patients according to their similar weight trajectory during their 4 years post-SG follow-up. Odd ratio (OR) and 95\% CI was calculated to assess strength of association between diabetes status and weight reduction age, sex, BMI and pre-surgery obesity comorbidities (hypertension, OSA and dyslipidemia. Statistical significance was set at $\mathrm{p}<0.05$.

Analyses were carried out using SigmaStat ${ }^{\circledR} 3.5$ (Systat Software, San Jose, CA, 8 USA), XLSTAT 2016 (Addinsoft, Brooklyn, NY) and R Software 3.6.0 (www.r-project.org). Growth mixture modeling was conducted using SAS software (PROC GLM, SAS Institute 2003) with Traj plug-in according to authors' recommendations (23).

\section{Results}

\section{Baseline characteristics according to T2D status}

At baseline, compared to patients without T2D ( $\mathrm{N}=221)$, those with $\mathrm{T} 2 \mathrm{D}(\mathrm{N}=152,40 \%)$ were significantly older, more frequently males and displayed higher prevalence of obesityrelated diseases such as obstructive sleep apnea (OSA), high blood pressure (HBP), dyslipidemia and cardiovascular diseases subsequently leading to a higher Framingham 10-year cardiovascular risk score (Table1). Despite comparable BMI, patients with T2D displayed lower percent total 
body-fat, but higher android-fat mass (\%).

\section{Weight-loss trajectories and body composition changes according to T2D status}

Weight-loss profile, starting from 3 months (3M) post-SG, significantly differed in patients with or without T2D (Figure 1A). Weight-loss expressed as \% from baseline was significantly lower in patients with T2D at 1-y (21\% vs. $27 \%, \mathrm{p}<10-3)$. Despite major inter-individual variability in both groups, patients with T2D showed a significantly worse weight-loss profile during the 1rst-year when compared to subjects without T2D ( $\mathrm{p}<10^{-3}$ Kolmogorov-Smirnov test)

(Figure 1B). Importantly, weight-loss at 2 years also significantly differed according to T2D status $(20 \%$ vs $26 \%$ in individuals with vs. without $\mathrm{T} 2 \mathrm{D}$ respectively $\mathrm{p}<0.0001)$.In the whole cohort during the complete follow-up, 5 profiles of weight-loss response were identified using a longitudinal growth mixture model (Figure 1C) in agreement with (5). "Very goodresponders" (14\%), "good-responders" (36\%), "mild-responders" (34\%) and "poorresponders" (13\%) respectively lost $40 \%, 30 \%, 20 \%$ and $10 \%$ of their initial body weight. Most patients categorized as "poor-responders" regained weight after the second year of follow-up (Figure 1C). Finally, 2\% were considered as a failure to SG since after a moderate weight-loss, they exceeded their pre-surgery weight during the follow-up (Group 1, Figure 1C). In accordance to our initial results, when comparing patients with weight-loss $>30 \%$ (thereafter called "good responders") to those with weight-loss $<20 \%$ (thereafter termed "poor responders"), we observed an increased prevalence of individuals with T2D in the "poor responders" group (52\% vs. $29 \%$ p $<10^{-3}$ Figure 1D). (). T2D remained significantly associated with poorer weight response after adjustment for age, sex, BMI and pre-surgery obesity-related comorbidities (hypertension, OSA, dyslipidemia and CVD) (Odd-Ratio=1.9 [1.1 - 3.2] p=0.01). Interestingly, 
weight regain after the first year was not significantly different according to T2D status. $17 \%$ of individuals with $\mathrm{T} 2 \mathrm{D}$ regained at least $5 \%$ as compared to $12 \%$ of patients without $\mathrm{T} 2 \mathrm{D}$ $(\mathrm{p}=0.379)$. Similarly, $6 \%$ of patients with T2D regained at least $10 \%$ as compared to $1 \%$ of patients without T2D $(\mathrm{p}=0.085)$.

Concerning body composition, FFM decreased significantly at $3 \mathrm{M}$ and remained stable until 12M, displaying a similar pattern in obese individuals with or without T2D (Figure 1E). By contrast, FM reduction, expressed as \% change from baseline in FM $(\mathrm{kg})$, was significantly lower in patients with vs. without T2D (Figure 1F) as early as 3M (-19 vs $-16 \%$ respectively, $\mathrm{p}<0.05)$. This difference was further exacerbated during the follow-up $\left(-24\right.$ vs $-29 \%\left(\mathrm{p}<10^{-2}\right)$ and -28 vs. $-37 \%\left(\mathrm{p}<10^{-3}\right)$ at 6 and 12 months, respectively).

\section{Influence of glucose control on weight-loss outcomes and body composition changes}

Weight-loss at 1-year was negatively correlated with baseline $\mathrm{HbA1c}\left(\mathrm{r}=-0.24, \mathrm{p}<10^{-2}\right)$. Furthermore, weight-loss was lower in patients with T2D above the glycemic target $(\mathrm{HbA} 1 \mathrm{c}>7 \%)$ before surgery (Figure $\mathbf{2 A}$ ) as compared to those below the target or to individuals without T2D, pointing at the negative impact of both T2D status and adverse glycemic control, despite similar BMI and FFM at baseline (Supplemental Figure 1A and B). Interestingly, glucose control also strongly influenced the amount of FM loss. It indeed deteriorated from patients without T2D to patients with T2D below or above the baseline target of $7 \%$ at both 6 and 12 months $\left(\mathrm{p}<10^{-3}\right.$, Figure 2B). The difference remained significant after adjustment for age, sex

and baseline \%FFM. Noteworthy, compared to patients with $\mathrm{Hbalc}<7 \%$, those above $7 \%$ displayed more severe T2D. Indeed, they displayed increased T2D duration ( $9.3 \pm 7.6$ vs. $4.9 \pm 5$ 
years, $\mathrm{p}<0.0001)$, increased number of glucose-lowering drugs $(2.1 \pm 1.1$ vs. $1.2 \pm 1, p<0.0001)$ at baseline and finally increased prevalence of insulin-therapy requirement at baseline (53\% vs. $11 \%, \mathrm{p}<0.0001)$ and at 1 -year ( $29 \%$ vs. $1 \%)$. T2D duration was not associated with weight-loss outcomes $(\mathrm{p}=0.84)$.

Due to baseline differences in adiposity and lower FM-loss in patients with T2D, both groups displayed similar body composition at 12M post-SG (Figure 2C), thus suggesting worse body composition improvement 1-year post-SG in individuals with T2D. Android FM also displayed significantly different reduction profiles in patients with or without T2D (65\% to $64 \%$ vs. $60 \%$ to $57 \%$ respectively from baseline to 12 months $p=0.001$; Figure $2 D$ ). These differences remained significant between groups after adjustment for age, sex and baseline FFM.

\section{Other surgical outcomes}

Despite poorer weight-loss, T2D individuals largely benefited from SG as seen with a $52 \%$ rate of diabetes remission at one year in our cohort. Furthermore, we did not evidence any differences in surgical adverse effects post-SG according to T2D status (Supplementary results and figure 2S)

\section{Discussion}

We herein show in a French BS cohort that both T2D status and poor pre-surgery glycemic control negatively impacts weight-loss and body composition changes post-SG. Compared to patients without T2D, individuals with T2D displayed lower improvement of their body composition, abdominal adipose tissue repartition and weight-loss. This was exacerbated in individuals with poorer glucose control. Nevertheless, post-surgery complication rate was similar in both groups. These results point at the importance of a strict glucose control before surgery not only to reduce hyperglycemia-related surgical complications (24) but also to optimize weight- 
loss..

We herein confirm that the amount of weight-loss and its trajectories post-SG display high variability, in agreement with other weight-loss interventions such as dietary interventions (25), adjustable gastric banding and RYGB $(2,26)$. Importantly, although the impact of T2D status on weight-loss post-SG had never been properly evaluated, previous research seemed in line with our current findings. Indeed, in two recent RCTs comparing SG and RYGB, the \% excess weight-loss at 5 years post-SG reached $61 \%$ in one and $49 \%$ in the second study. Differences in weight-loss outcome could originate from the 2-fold higher percentage of T2D individuals included at baseline in the first study (11) (i.e. 43 vs. $24 \%$ in the first vs. the second study, respectively) (3,11). T2D status-associated lesser weight-loss represents an important information for routine clinical care. It is indeed critical to better acknowledge expected weightloss outcomes, on top of glycemic profile improvements (27), especially now that BS is included in the T2D treatment algorithm (8).

Since, pre-surgery glucose homeostasis negatively influences weight-loss even when most clinical confounding factors are taken into account, this pleads for optimizing glycemic control before BS. One could hypothesize that patients with poorer glycemic control are below their optimal weight before surgery. BS will first enable the improvement of their glucose homeostasis (28), thus subsequently limiting weight-loss. Indeed, poor glycemic control has previously been associated with increased basal metabolic rate (29). Furthermore, uncontrolled diabetes-related increased glycosuria is also associated with weight-loss $(29,30)$, however glycosuria was not assessed herein. Nevertheless, while BS seems to perform lower in individual with T2D, BS has shown its superiority over intensive medical therapy in several RCTs including 
SG (31-34), thus pointing at the benefit for these patients to undergo BS, which present similar rates of surgical complications in individuals with or without T2D. Importantly, the choice of BS type remains open, to date. .

Our results stimulate the need to develop and evaluate add-on strategies, proposed after BS to further improve weight-outcomes in T2D patients. Some first line of evidence already supports this claim in general BS candidates. For example, adherence to Mediterranean diet postsurgery significantly improved weight-loss response at 1-year, after RYGB or SG (35). However, this was not specifically tested in individuals with T2D. Likewise, exercise training programs started post-BS are able to optimize weight-loss responses (36): patients with high-adherence to moderate or intense physical activity post-BS displayed better weight-loss outcomes (37). Addon physical activity training program after the 1 st-year post-BS also prevent weight regain (38). Finally, the adjunction of GLP1-R agonist (compared to placebo) induces improved weight-loss in individuals who underwent BS and remained with T2D 2 years post-surgery (39). These strategies should now be further tested in T2D individuals' candidates to SG.

Importantly, body composition and fat distribution amelioration post-BS $(14,40)$, which we also herein observe, is better to predict health outcomes and mortality risk than BMI or weightloss per se $(41,42)$. We can speculate that our observed limited reduction in visceral fat in T2D individuals could be less favorable for cardiometabolic outcomes in the long term post-SG (43). Nevertheless, despite this poorer response in individuals with T2D, most of them display major improvement in glycemic control (either engaging in diabetes remission or improving their HbA1c while reducing the number of glucose-lowering agent) (44). Furthermore, on top of weight-loss and metabolic improvements, individuals with T2D undergoing all types of BS also 
reduced their T2D-related cardiovascular complications (45) and their risks of developing macrovascular events during a 5-years follow-up, as compared to patients with T2D not undergoing BS (46). Although weight reduction and FM loss post-SG might be lower in individuals with T2D, a majority of them metabolically benefit from BS (44) while they could eventually benefit even more with an optimized weight-loss synergic intervention. Finally, literature has previously shown that BS enables cost reduction in T2D follow-up as compared to before surgery (47) or to medical therapy alone (48), again pointing at the benefit for T2D individuals to undergo BS.

In conclusion, although $\mathrm{SG}$ is generally efficient to induce weight reduction and improvement of obesity-related diseases, weight-loss is lower in individuals with T2D, especially in those with uncontrolled diabetes prior to the surgery. Nevertheless, these patients still benefit from overall metabolic improvement and display similar rate of surgical complications than individuals without T2D. Our work paves the way for optimization of T2D follow-up in this context. 
Author contributions. JAW designed the study. CP, CC, JMO, KC, JAW contributed to patient recruitment and coordinated clinical investigation, patient phenotyping, and sample collection. MD and JAW analyzed data. MD, KC and JAW wrote the manuscript. LG and JLB operated patients. $\mathrm{MD}, \mathrm{CP}, \mathrm{CC}, \mathrm{CA}, \mathrm{JMO}, \mathrm{KC}$ and $\mathrm{JAW}$ contributed to data presentation and the manuscript.

All authors reviewed the manuscript. JAW is the guarantor of this work and, as such, had full access to all the data in the study and takes responsibility for the integrity of the data and the accuracy of the data analysis. 



\section{References}

1. Sjöström L. Review of the key results from the Swedish Obese Subjects (SOS) trial - a prospective controlled intervention study of bariatric surgery. J Intern Med. 2013 Mar;273(3): 219-34.

2. Courcoulas AP, King WC, Belle SH, Berk P, Flum DR, Garcia L, et al. Seven-Year Weight Trajectories and Health Outcomes in the Longitudinal Assessment of Bariatric Surgery (LABS) Study. JAMA Surg. 2017 Dec 6;

3. Peterli R, Wölnerhanssen BK, Peters T, Vetter D, Kröll D, Borbély Y, et al. Effect of Laparoscopic Sleeve Gastrectomy vs Laparoscopic Roux-en-Y Gastric Bypass on Weight Loss in Patients With Morbid Obesity: The SM-BOSS Randomized Clinical Trial. JAMA. 2018 16;319(3):255-65.

4. Courcoulas AP, Christian NJ, O'Rourke RW, Dakin G, Patchen Dellinger E, Flum DR, et al. Preoperative factors and 3-year weight change in the Longitudinal Assessment of Bariatric Surgery (LABS) consortium. Surg Obes Relat Dis Off J Am Soc Bariatr Surg. 2015 Oct;11(5): $1109-18$.

5. Courcoulas AP, Christian NJ, Belle SH, Berk PD, Flum DR, Garcia L, et al. Weight change and health outcomes at 3 years after bariatric surgery among individuals with severe obesity. JAMA. 2013 Dec 11;310(22):2416-25.

6. Abdennour M, Reggio S, Le Naour G, Liu Y, Poitou C, Aron-Wisnewsky J, et al. Association of adipose tissue and liver fibrosis with tissue stiffness in morbid obesity: links with diabetes and BMI loss after gastric bypass. J Clin Endocrinol Metab. 2014 Mar;99(3):898-907.

7. Bel Lassen P, Charlotte F, Liu Y, Bedossa P, le Naour G, Tordjman J, et al. The FAT score, a Fibrosis score of Adipose Tissue: predicting weight loss outcome after gastric bypass. J Clin Endocrinol Metab. 2017 Apr 17;

8. Schauer PR, Mingrone G, Ikramuddin S, Wolfe B. Clinical Outcomes of Metabolic Surgery: Efficacy of Glycemic Control, Weight Loss, and Remission of Diabetes. Diabetes Care. 2016 Jun;39(6):902-11.

9. Angrisani L, Santonicola A, Iovino P, Vitiello A, Zundel N, Buchwald H, et al. Bariatric Surgery and Endoluminal Procedures: IFSO Worldwide Survey 2014. Obes Surg. 2017 Sep; 27(9):2279-89.

10. Osland E, Yunus RM, Khan S, Memon B, Memon MA. Weight Loss Outcomes in Laparoscopic Vertical Sleeve Gastrectomy (LVSG) Versus Laparoscopic Roux-en-Y Gastric Bypass (LRYGB) Procedures: A Meta-Analysis and Systematic Review of Randomized Controlled Trials. Surg Laparosc Endosc Percutan Tech. 2017 Feb;27(1):8-18.

11. Salminen P, Helmiö M, Ovaska J, Juuti A, Leivonen M, Peromaa-Haavisto P, et al. Effect of Laparoscopic Sleeve Gastrectomy vs Laparoscopic Roux-en-Y Gastric Bypass on Weight Loss at 5 Years Among Patients With Morbid Obesity: The SLEEVEPASS Randomized Clinical Trial. JAMA. 2018 16;319(3):241-54.

12. Aminian A, Zajichek A, Arterburn DE, Wolski KE, Brethauer SA, Schauer PR, et al. Association of Metabolic Surgery With Major Adverse Cardiovascular Outcomes in Patients With Type 2 Diabetes and Obesity. JAMA. 2019 Sep 2;

13. Gepner Y, Shelef I, Schwarzfuchs D, Zelicha H, Tene L, Yaskolka Meir A, et al. Effect of Distinct Lifestyle Interventions on Mobilization of Fat Storage Pools: CENTRAL Magnetic 
Resonance Imaging Randomized Controlled Trial. Circulation. 2018 13;137(11):1143-57.

14. Verger EO, Aron-Wisnewsky J, Dao MC, Kayser BD, Oppert J-M, Bouillot J-L, et al. Micronutrient and Protein Deficiencies After Gastric Bypass and Sleeve Gastrectomy: a 1-year Follow-up. Obes Surg. 2015 Jul 24;

15. Liu Y, Aron-Wisnewsky J, Marcelin G, Genser L, Le Naour G, Torcivia A, et al. Accumulation and Changes in Composition of Collagens in Subcutaneous Adipose Tissue After Bariatric Surgery. J Clin Endocrinol Metab. 2016 Jan;101(1):293-304.

16. Thereaux J, Corigliano N, Poitou C, Oppert J-M, Czernichow S, Bouillot J-L. Five-year weight loss in primary gastric bypass and revisional gastric bypass for failed adjustable gastric banding: results of a case-matched study. Surg Obes Relat Dis Off J Am Soc Bariatr Surg. 2015 Feb;11(1):19-25.

17. Wijngaarden LH, Jonker FHW, van den Berg JW, van Rossem CC, van der Harst E, Klaassen RA. Impact of initial response of laparoscopic adjustable gastric banding on outcomes of revisional laparoscopic Roux-en-Y gastric bypass for morbid obesity. Surg Obes Relat Dis Off J Am Soc Bariatr Surg. 2017 Apr;13(4):594-9.

18. Dardamanis D, Navez J, Coubeau L, Navez B. A Retrospective Comparative Study of Primary Versus Revisional Roux-en-Y Gastric Bypass: Long-Term Results. Obes Surg. 2018;28(8):2457-64.

19. Mechanick JI, Apovian C, Brethauer S, Timothy Garvey W, Joffe AM, Kim J, et al. Clinical Practice Guidelines for the Perioperative Nutrition, Metabolic, and Nonsurgical Support of Patients Undergoing Bariatric Procedures - 2019 Update: Cosponsored by American Association of Clinical Endocrinologists/American College of Endocrinology, The Obesity Society, American Society for Metabolic and Bariatric Surgery, Obesity Medicine Association, and American Society of Anesthesiologists. Obes Silver Spring Md. 2020 Apr;28(4):O1-58.

20. Vignot M, Bernat M, Oppert J-M, Basdevant Oppert A, Aron-Wisnewsky J. [The care pathway in weight loss surgery]. Soins Rev Ref Infirm. 2016 Dec;61(811):37-8.

21. Thereaux J, Corigliano N, Poitou C, Oppert J-M, Czernichow S, Bouillot J-L. Comparison of results after one year between sleeve gastrectomy and gastric bypass in patients with BMI $\geq$ $50 \mathrm{~kg} / \mathrm{m}^{2}$. Surg Obes Relat Dis Off J Am Soc Bariatr Surg. 2015 Aug;11(4):785-90.

22. Oppert J-M, Bellicha A, Roda C, Bouillot J-L, Torcivia A, Clement K, et al. Resistance Training and Protein Supplementation Increase Strength After Bariatric Surgery: A Randomized Controlled Trial. Obes Silver Spring Md. 2018;26(11):1709-20.

23. JONES BL, NAGIN DS, ROEDER K. A SAS Procedure Based on Mixture Models for Estimating Developmental Trajectories. Sociol Methods Res. 2001 Feb 1;29(3):374-93.

24. Rometo D, Korytkowski M. Perioperative Glycemic Management of Patients Undergoing Bariatric Surgery. Curr Diab Rep. 2016 Apr;16(4):23.

25. Batterham M, Tapsell LC, Charlton KE. Baseline characteristics associated with different BMI trajectories in weight loss trials: a case for better targeting of interventions. Eur J Clin Nutr. 2016 Feb;70(2):207-11.

26. Sjöström L, Peltonen M, Jacobson P, Sjöström CD, Karason K, Wedel H, et al. Bariatric surgery and long-term cardiovascular events. JAMA. 2012 Jan 4;307(1):56-65.

27. Dicker D, Yahalom R, Comaneshter DS, Vinker S. Long-Term Outcomes of Three Types of Bariatric Surgery on Obesity and Type 2 Diabetes Control and Remission. Obes Surg. 2016 Aug; 
26(8):1814-20.

28. Pories WJ, Swanson MS, MacDonald KG, Long SB, Morris PG, Brown BM, et al. Who would have thought it? An operation proves to be the most effective therapy for adult-onset diabetes mellitus. Ann Surg. 1995 Sep;222(3):339-50; discussion 350-352.

29. Mäkimattila S, Nikkilä K, Yki-Järvinen H. Causes of weight gain during insulin therapy with and without metformin in patients with Type II diabetes mellitus. Diabetologia. 1999 Apr; 42(4):406-12.

30. Van Gaal L, Scheen A. Weight management in type 2 diabetes: current and emerging approaches to treatment. Diabetes Care. 2015 Jun;38(6):1161-72.

31. Schauer PR, Bhatt DL, Kirwan JP, Wolski K, Brethauer SA, Navaneethan SD, et al. Bariatric surgery versus intensive medical therapy for diabetes--3-year outcomes. N Engl J Med. 2014 May 22;370(21):2002-13.

32. Schauer PR, Bhatt DL, Kirwan JP, Wolski K, Aminian A, Brethauer SA, et al. Bariatric Surgery versus Intensive Medical Therapy for Diabetes - 5-Year Outcomes. N Engl J Med. 2017 16;376(7):641-51.

33. Mingrone G, Panunzi S, De Gaetano A, Guidone C, Iaconelli A, Leccesi L, et al. Bariatric surgery versus conventional medical therapy for type 2 diabetes. N Engl J Med. 2012 Apr 26;366(17):1577-85.

34. Mingrone G, Panunzi S, De Gaetano A, Guidone C, Iaconelli A, Nanni G, et al. Bariatricmetabolic surgery versus conventional medical treatment in obese patients with type 2 diabetes: 5 year follow-up of an open-label, single-centre, randomised controlled trial. Lancet Lond Engl. 2015 Sep 5;386(9997):964-73.

35. Gils Contreras A, Bonada Sanjaume A, Becerra-Tomás N, Salas-Salvadó J. Adherence to Mediterranean Diet or Physical Activity After Bariatric Surgery and Its Effects on Weight Loss, Quality of Life, and Food Tolerance. Obes Surg. 2020 Feb;30(2):687-96.

36. Bellicha A, Ciangura C, Poitou C, Portero P, Oppert J-M. Effectiveness of exercise training after bariatric surgery-a systematic literature review and meta-analysis. Obes Rev Off J Int Assoc Study Obes. 2018;19(11):1544-56.

37. Fontana AD, Lopes AD, Lunardi AC. Bariatric Surgery Associated with Practice of Moderate to Intense Physical Activity Related to Weight Loss, Activity Level in Daily Life, Dyspnea, and Quality of Life of Sedentary Individuals with Morbid Obesity: a Prospective Longitudinal Study. Obes Surg. 2019;29(8):2442-8.

38. Marc-Hernández A, Ruiz-Tovar J, Aracil A, Guillén S, Moya-Ramón M. Effects of a HighIntensity Exercise Program on Weight Regain and Cardio-metabolic Profile after 3 Years of Bariatric Surgery: A Randomized Trial. Sci Rep. 2020 Feb 20;10(1):3123.

39. Miras AD, Pérez-Pevida B, Aldhwayan M, Kamocka A, McGlone ER, Al-Najim W, et al. Adjunctive liraglutide treatment in patients with persistent or recurrent type 2 diabetes after metabolic surgery (GRAVITAS): a randomised, double-blind, placebo-controlled trial. Lancet Diabetes Endocrinol. 2019 Jul;7(7):549-59.

40. Keidar A, Hershkop KJ, Marko L, Schweiger C, Hecht L, Bartov N, et al. Roux-en-Y gastric bypass vs sleeve gastrectomy for obese patients with type 2 diabetes: a randomised trial. Diabetologia. 2013 Sep;56(9):1914-8.

41. Thibault R, Pichard C. The evaluation of body composition: a useful tool for clinical 
practice. Ann Nutr Metab. 2012;60(1):6-16.

42. Heitmann BL, Erikson H, Ellsinger BM, Mikkelsen KL, Larsson B. Mortality associated with body fat, fat-free mass and body mass index among 60-year-old swedish men-a 22-year follow-up. The study of men born in 1913. Int J Obes Relat Metab Disord J Int Assoc Study Obes. 2000 Jan;24(1):33-7.

43. Sjöström CD, Lissner L, Sjöström L. Relationships between changes in body composition and changes in cardiovascular risk factors: the SOS Intervention Study. Swedish Obese Subjects. Obes Res. 1997 Nov;5(6):519-30.

44. Aminian A, Brethauer SA, Andalib A, Nowacki AS, Jimenez A, Corcelles R, et al. Individualized Metabolic Surgery Score: Procedure Selection Based on Diabetes Severity. Ann Surg. 2017;266(4):650-7.

45. Romeo S, Maglio C, Burza MA, Pirazzi C, Sjöholm K, Jacobson P, et al. Cardiovascular events after bariatric surgery in obese subjects with type 2 diabetes. Diabetes Care. 2012 Dec; 35(12):2613-7.

46. Fisher DP, Johnson E, Haneuse S, Arterburn D, Coleman KJ, O'Connor PJ, et al. Association Between Bariatric Surgery and Macrovascular Disease Outcomes in Patients With Type 2 Diabetes and Severe Obesity. JAMA. 2018 16;320(15):1570-82.

47. Gesquiere I, Aron-Wisnewsky J, Foulon V, Haggege S, Van der Schueren B, Augustijns P, et al. Medication Cost is Significantly Reduced After Roux-en-Y Gastric Bypass in Obese Patients. Obes Surg. 2014 Jun 20;

48. Neovius M, Narbro K, Keating C, Peltonen M, Sjöholm K, Agren G, et al. Health care use during 20 years following bariatric surgery. JAMA. 2012 Sep 19;308(11):1132-41. 
Tables

Table 1: Pre-surgery clinical characteristics of patients from the Barican cohort, comparing individuals with obesity with or without T2D undergoing SG.

\begin{tabular}{|c|c|c|c|}
\hline & $\begin{array}{l}\text { Controls } \\
(\mathrm{n}=221)\end{array}$ & $\begin{array}{l}T 2 D(n= \\
152)\end{array}$ & P Value \\
\hline Female Sex n $(\%)$ & $172(78)$ & $100(66)$ & $<0.01$ \\
\hline Age (years) & $42 \pm 12$ & $50 \pm 11$ & $<0.0001$ \\
\hline $\operatorname{BMI}\left(\mathrm{kg} / \mathrm{m}^{2}\right)$ & $45 \pm 8$ & $46.8 \pm 9$ & 0.09 \\
\hline High blood pressure $\mathrm{n}(\%)$ & $81(39)$ & $113(76)$ & $<0.0001$ \\
\hline With medication n $(\%)$ & $76(94)$ & $112(99)$ & 0.08 \\
\hline Number of drugs & $2.0 \pm 1.1$ & $2.4 \pm 1.0$ & $<0.01$ \\
\hline Dyslipidemia n (\%) & $167(81)$ & $137(93)$ & $<0.01$ \\
\hline With medication n (\%) & $37(22)$ & $110(66)$ & $<0.0001$ \\
\hline Sleep apnea syndrome n $(\%)$ & $102(49)$ & $124(84)$ & $<0.0001$ \\
\hline CPAP n(\%) & $44(43)$ & $71(57)$ & $<0.0001$ \\
\hline Cardio-Vascular Diseases n (\%) & $8(4)$ & $20(14)$ & 0.001 \\
\hline $\begin{array}{l}\text { Framingham 10-year cardiovascular risk } \\
\text { score }\end{array}$ & $4.5 \pm 3.9$ & $19.7 \pm 11.0$ & $<0.0001$ \\
\hline Systemic Diseases n (\%) & $37(17)$ & $36(24)$ & 0.106 \\
\hline Joint Diseases n (\%) & $23(11)$ & $26(18)$ & 0.065 \\
\hline Stable Depression n (\%) & $41(19)$ & $35(24)$ & 0.313 \\
\hline \multicolumn{4}{|l|}{ Diabetes characteristics } \\
\hline HbA1c $(\%)$ & $5.7 \pm 0.3$ & $7.3 \pm 1.3$ & $<0.0001$ \\
\hline Duration of T2D (years) & & $7.2 \pm 6.8$ & \\
\hline Number of drugs (n) & & $1.1 \pm 1.2$ & \\
\hline On insulin therapy $\mathrm{n}(\%)$ & & $50(33)$ & \\
\hline Body composition & $n=173$ & $n=108$ & \\
\hline
\end{tabular}




\begin{tabular}{llll} 
Female Sex n (\%) & $140(81)$ & $76(70)$ & 0.041 \\
Age (years) & $43 \pm 13$ & $50 \pm 11$ & $<0.0001$ \\
Percent body fat Mass (\%) & $48 \pm 5$ & $46 \pm 6$ & $<0.0001$ \\
Android Fat (\% of total fat mass) & $60 \pm 6$ & $66 \pm 8$ & $<0.0001$ \\
\hline
\end{tabular}

BMI body mass index. HbA1c glycated hemoglobin. CPAP Continuous Positive Airway Pressure. T2D type 2 diabetes. 


\section{Figure legend}

Fig. 1: Weight-loss post and body composition changes sleeve gastrectomy: contribution of T2D status

(a) Percent weight-loss following sleeve gastrectomy (SG) in patients with (black circles) and without (white circles) Type 2 diabetes (percentage from baseline weight). Mean $\pm \mathrm{SEM}$ are indicated to show difference of means. Subjects variability being underlined in Figure 1(b).

(b) Percent weight-loss distribution curves for patients with (solid line) and without (dashed lines) Type 2 diabetes one year after sleeve gastrectomy (Kolmogorov-Smirnov test p-value $<$ $0.0001)$.

(c) Percent weight change trajectories using growth mixture models (observed median (interquartile range)).

(d) Percentage of Type 2 diabetes patients among good (groups 4-5) and poor responders (groups $1-3)$.

(e) Percent fat-free mass loss following sleeve gastrectomy in patients with (black bars) and without (white bars, $\mathrm{n}=173$ ) Type 2 diabetes (percentage from baseline fat-free mass).

(f) Percent fat mass loss following sleeve gastrectomy in patients with (black bars, n=108) and without (white bars, $n=173$ ) Type 2 diabetes (percentage from baseline fat mass).

${ }^{*} \mathrm{p}<0.05, * * * \mathrm{p}<0.001$. ND non-diabetic. T2D: type 2 diabetes. GR: good responders. PR: poor responders. m month. y year. HbA1c Glycated hemoglobin.

Fig. 2: Weight-loss and body composition changes from baseline to one-year post-sleeve 


\section{gastrectomy: impact of glucose control}

(a) Percent weight-loss one year after sleeve gastrectomy according to Type 2 diabetes status and baseline HbA1c increasing values solely for patients with T2D.

(b) Percent fat mass loss following sleeve gastrectomy at 3,6 and 12 months in patients with type 2 diabetes patients according to baseline $\mathrm{HbA1c}(\mathrm{HbA} 1 \mathrm{c}<7 \%$ grey bars, $\mathrm{n}=46, \mathrm{HbA} 1 \mathrm{c}>7 \%$ black bars, $n=62$ ) and in patients without T2D (white bars, $n=173$ ) subjects (percentage from baseline fat mass).

(c) Body composition at baseline and 12 months after sleeve gastrectomy, displaying fat mass (grey) and fat-free mass proportion (black) according to Type 2 diabetes status.

(d) Evolution of android fat mass proportion in patients with (black bars) and without (white bars) Type 2 diabetes subjects (percentage from baseline proportion, see Methods for details). ${ }^{*} \mathrm{p}<0.05, * * \mathrm{p}<0.01, * * * \mathrm{p}<0.001$, NS not significant. FFM fat-free mass. FM fat mass. ND non-diabetic. T2D type 2 diabetic.

\section{Supplementary figure legend}

Supplementary figure 1: A. BMI values according to baseline HbA1c below or above 7\% in individuals with T2D represented as mean \pm SD. B. Fat-free mass (in \%) values according to baseline $\mathrm{HbA} 1 \mathrm{c}$ below or above $7 \%$ in individuals with $\mathrm{T} 2 \mathrm{D}$ represented as mean $\pm \mathrm{SD}$. BMI for body mass index; FFM for Fat mass (\% or overall weight).

Supplementary figure 2: Prevalence of complications post-surgery according to diabetes status.

Digestive symptoms include the cumulative prevalence of constipation, diarrhea, abdominal pain and vomiting, which prevalence are also displayed individually. Surgical complication include 
the cumulative prevalence of fistula, leakage, medio-gastric stenosis, ulcer, hemorrhage, peritonitis, occlusion, abces, and other (pneunomopathy and pyelonephritis). Acid reflux prevalence is displayed on its own. Light grey stands for individuals with T2D and black for those without. ${ }^{* *}=$ p-value $<0.01$ for T2D vs controls. 
=igure 2

A
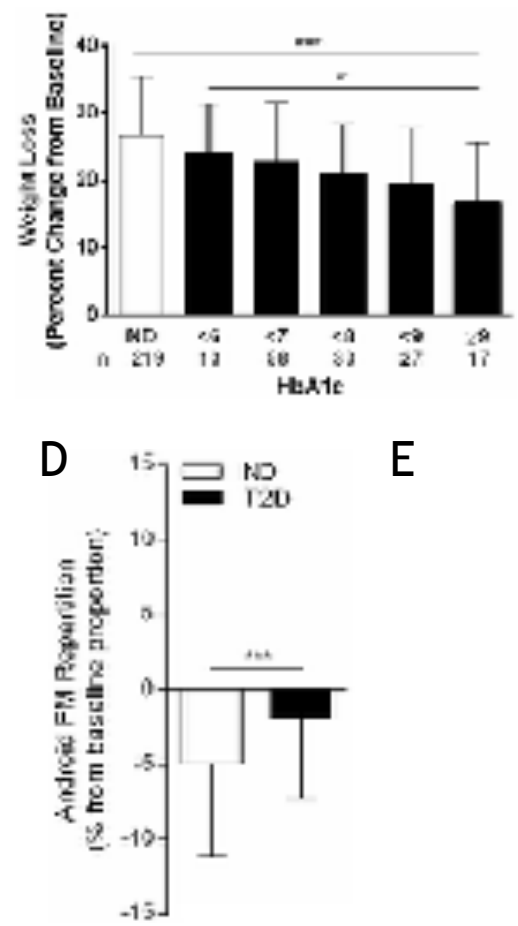

B

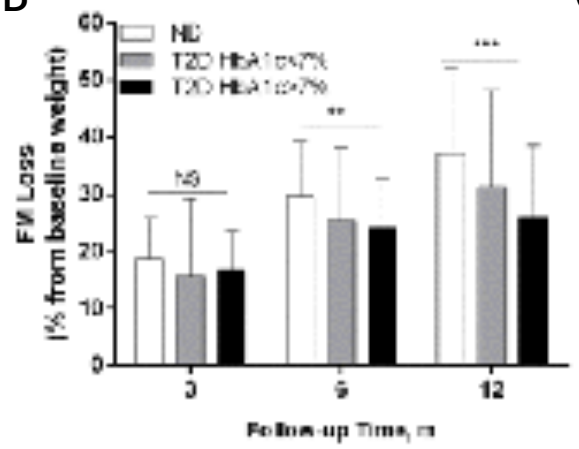

E
C

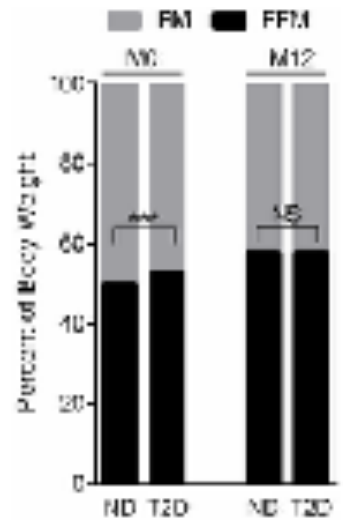


Supplemental material

Supplemental Figure 1: Anthropometric measures in individuals with $\mathrm{T} 2 \mathrm{D}$ according to their baseline $\mathrm{HbA1c}$

A

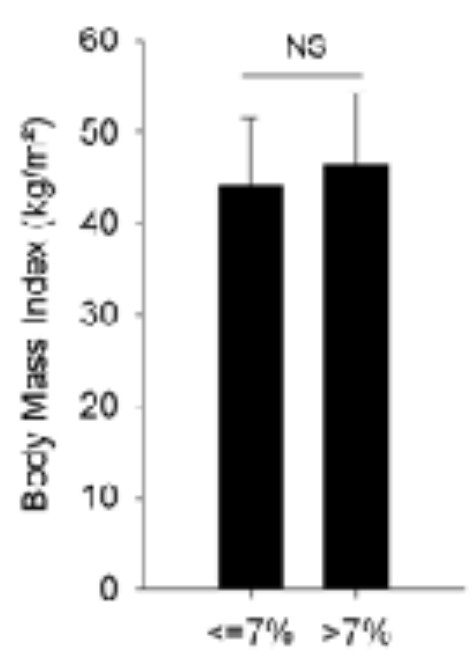

B

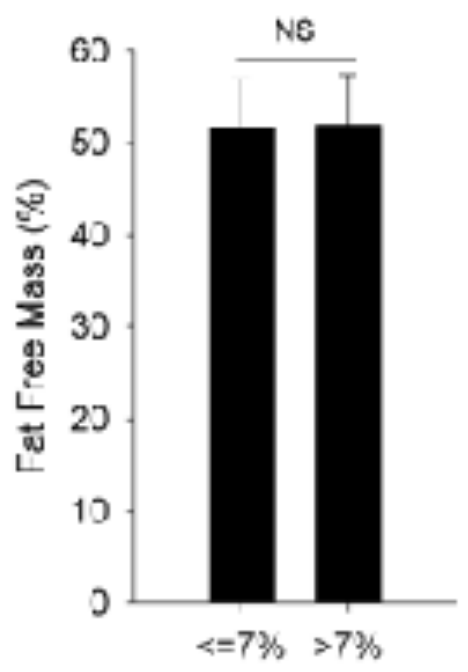




\section{Supplemental material}

Supplemental Figure 2: prevalence of surgical complications after Sleeve according Type 2 Diabetes

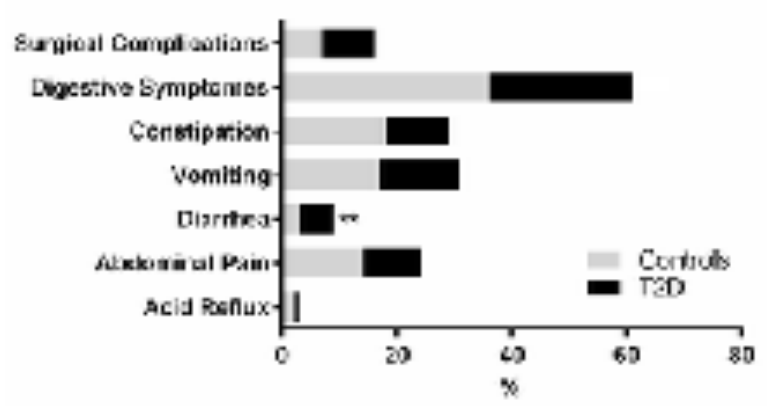

